\title{
PEMANFAATAN TEKNOLOGI INFORMASI DAN KOMUNIKASI (TIK) OLEH GURU DI SEKOLAH PENERIMA UNIVERSAL SERVICE OBLIGATION (USO)
}

\author{
Rica Yanuarti ${ }^{1}$ dan Rusman ${ }^{2}$ \\ ${ }^{1}$ Pustekkom - Kemendikbud dan ${ }^{2}$ Universitas Pendidikan Indonesia \\ e-mail: rica.yanuarti@kemdikbud.go.id
}

\begin{abstract}
Abstrak
Di Indonesia terdapat 122 kabupaten yang termasuk kategori wilayah tertinggal, terdepan, terluar (3T). Wilayah tersebut harus dipastikan mendapat akses pendidikan yang setara dengan wilayah lainnya. Salah satu upaya pemerintah adalah dengan mengintegrasikan teknologi informasi dan komunikasi (TIK) dalam program Universal Service Obligation (USO) untuk pendidikan di wilayah 3T. Penelitian bertujuan untuk menginvestigasi sejauh mana pemanfaatan TIK dan akses internet, oleh guru di sekolah penerima USO. Metode yang digunakan adalah survei penyebaran angket kepada guru di sekolah USO, ditambah studi dokumentasi. Data dihasilkan dari 141 orang guru responden kemudian dianalisis secara deskriptif. Hasil kajian menunjukkan bahwa mayoritas responden guru (82.9\%) sudah menggunakan alat bantu mengajar berbasis TIK. Hasil dari penelitian ini adalah perlunya fasilitasi dan sinergi secara sistemik agar pemanfaatan TIK di sekolah USO semakin meluas. Rekomendasi untuk riset selanjutnya adalah disarankan mengambil responden dan korelasi data yang lebih besar agar hasil penelitian dapat digeneralisasi.
\end{abstract}

Kata Kunci: Teknologi Informasi dan Komunikasi (TIK), akses internet, wilayah 3T, Universal Service Obligation (USO)

\section{UTILIZATION OF INFORMATION AND COMMUNICATION (ICT) BY TEACHERS IN UNIVERSAL SERVICE OBLIGATION (USO) SCHOOLS}

\begin{abstract}
There are 122 regencies in Indonesia that belonging to the category of disadvantaged, frontier, remoted (3T) regions. Those regions should be accessed to education equivalent to other regions. One of the government's efforts is to integrate information and communication technology (ICT) within education in $3 T$ regions named Universal Service Obligation (USO) programme. The study attempt to investigate the effectiveness of ICT and internet access utilization, by teachers at USO schools. The method used was distributing questionnaires to survey teachers in USO schools, supplemented by documentary studies. Data generated from 141 respondent and analyzed descriptively. The results show that the majority of the respondent (82.9\%) have used ICT-based teaching aids. The result of this research is the need for systemic facilitation and synergy to widespread the ICT utilization in USO schools. Recommendation for further research, it is advisable to take the more respondent and correlate the bigger data so that the research result can be generalized.
\end{abstract}

Keywords: Information and Communication Technology (ICT), internet access, $3 T$ regions, Universal Service Obligation (USO)

\section{PENDAHULUAN}

Abad 21 yang tengah berlangsung saat ini sangat erat dengan istilah globalisasi. Beragam bidang kehidupan, termasuk pendidikan, terkena dampak globalisasi yakni transformasi sistemik. Definisi globalisasi menurut OECD (The Organization for Economic Cooperation and Development) adalah gambaran peningkatan internasionalisasi pasar untuk 
barang dan jasa, sarana produksi, sistem keuangan, persaingan, perusahaan, teknologi, dan industri. Rizvi dkk (2005) menafsirkan globalisasi sebagai proses sosial dan fenomenologis yang diawali dari gerakan ekonomi berupa integrasi pasar, kapitalisme modern yang lebih terbuka, trans-nasional, serta dipengaruhi oleh pesatnya perkembangan teknologi. Globalisasi menggambarkan kondisi dunia yang saling terhubung dan ketergantungan karena mengaburnya batas negara, serta proses pertukaran komoditas yang makin cepat dan instan.

Ciri-ciri globalisasi antara lain informasional, berjejaring, berbasis pengetahuan, post-industrial, dan berorientasi layanan. Selain terkait erat dengan ekonomi dan politik, globalisasi juga memiliki dampak budaya dan pendidikan, karena kepentingan budaya melekat pada pendidikan (Wong ed., 2006). Pengaruh globalisasi dalam pendidikan diawali dengan maraknya upaya riset dan pengembangan untuk menghasilkan produk-produk yang memiliki nilai tambah, sarat akan muatan ilmu pengetahuan mutakhir, sehingga unggul dan berpeluang untuk memenangkan pasar (BSNP, 2010).

Persaingan, gerakan ekonomi, dan kesetaraan global turut mendorong terjadinya reformasi pendidikan. Bentukbentuk reformasi untuk peningkatan pendidikan adalah desentralisasi, standarisasi, peningkatan manajemen dan sumber daya, kompetensi guru, hingga pemanfaatan teknologi (Carnoy, 1999). Untuk mencapai tatanan global, suatu bangsa-negara perlu mempersiapkan diri dengan baik pada level lokal (nasional). Hal ini dikenal dengan kerangka kerja etik think globally act locally yang bersifat universal sekaligus berkelanjutan (Hudson, 2010; Galli dkk, 2018).

Di Indonesia, pembangunan nasional juga didasari oleh wawasan global. Pendidikan memiliki peranan strategis dalam pembangunan nasional dan dijadikan sebagai investasi terbentuknya SDM berkualitas. Melalui pendidikan yang baik, diharapkan tercipta manusia sebagai pelaku pembangunan yang berjiwa pembaharu, yang dapat mengembangkan segala potensi diri dan mengambil peran dalam pembangunan berbagai aspek kehidupan (BPS, 2017).

Tantangan dalam membangun pendidikan nasional adalah peningkatan kualitas dan pemerataan pendidikan sesuai tujuan global Sustainable Development Goals (SDG). Dikatakan sebagai tantangan karena Indonesia merupakan negara dengan jumlah penduduk sangat banyak yang tersebar di 17.899 pulau, dan hanya 10 yang termasuk pulau besar (Warsihna, 2013). Persebaran penduduk yang masih terpusat di wilayah tertentu, kondisi geografis beragam membuat kualitas maupun kuantitas aspek pendidikan di Indonesia belum merata. Standar pendidikan nasional menyebutkan pentingnya kesetaraan dalam layanan, fasilitas, hingga akses untuk pendidikan di semua wilayah bagi seluruh warga. Sedangkan di Indonesia masih ada daerah yang sulit dijangkau karena terpencil, terdepan, dan terluar (3T) yang memiliki hak untuk mendapat layanan pendidikan yang sama dengan wilayah lain. Salah satu upaya pemerataan pendidikan di wilayah 3T adalah dengan memanfaatkan teknologi informasi dan komunikasi (TIK) untuk pendidikan dan pembelajaran.

Fokus penelitian ini adalah pemanfaatan TIK di wilayah 3T yang dilaksanakan melalui program Kewajiban Pelayanan Universal atau Universal Service Obligation (USO). Program USO bidang pendidikan diinisiasi sejak tahun 2015 oleh Kementerian Pendidikan dan Kebudayaan (Kemendikbud) bekerjasama dengan Kementerian Komunikasi dan Informatika (Kemkominfo). Sinergitas dua kementerian ini bertujuan untuk mewujudkan percepatan penyediaan akses internet secara berkelanjutan dalam rangka peningkatan kualitas pembelajaran di sekolah, khususnya di daerah 3T. Serta upaya mewujudkan salah satu agenda Nawacita yang dicanangkan presiden Republik Indonesia. Dua dasar hukum 
program USO bidang pendidikan adalah: 1) Nota Kesepahaman antara Kemendikbud dan Kemkominfo No.583/ M.KOMINFO/HK.03.02/8/2015 \& No. 06/VIII/NK/2015 tentang Pemanfaatan Teknologi Informasi dan Komunikasi untuk Meningkatkan Kualitas Pendidikan dan Kebudayaan, dan 2) Perjanjian Kerjasama antara Sesjen Kemendikbud dengan Dirjen PPI Kemkominfo terkait penyediaan akses internet dalam rangka peningkatan kualitas pembelajaran di sekolah 3T melalui program Universal Service Obligation (USO) atau kontribusi Kewajiban Pelayanan Universal (KPU).

Pemerintah menyatakan ada 122 kabupaten yang masuk dalam kategori wilayah 3T dalam Perpres No.131 Tahun 2015 tentang Penetapan Daerah Tertinggal Tahun 2015-2019. Program USO menyasar sekolah tingkat SD, SMP, SMA, maupun SMK di wilayah 3T agar memiliki fasilitas TIK yang dapat dimanfaatkan untuk pendidikan, baik e-pembelajaran maupun e-administrasi. Layanan TIK yang dimaksud dalam program USO adalah gelaran akses internet sekolah. Tidak sesederhana memberikan bantuan akses saja, program layanan TIK dalam USO bersifat sistemik meliputi regulasi dan kebijakan; peren-canaan; sarana dan prasarana; penguatan SDM; dan evaluasi. Semua komponen sistem layanan harus dipenuhi oleh dua instansi penyelenggara USO dalam bentuk pelaksanaan kewajiban berupa pendataan terpadu; penyiapan fasilitas dasar (infrastruktur, komputer, dan jaringan); pelatihan TIK bagi guru dan tenaga kependidikan (tendik); pemberian dukungan teknis dan helpdesk; serta pengendalian, monitoring dan evaluasi.

Internet kini menjadi trend global. Namun akses internet dipilih sebagai layanan pendidikan program USO karena kebutuhan yang dapat difasilitasi internet memang semakin tinggi. Kehadiran internet memudahkan perolehan dan penyerapan pengetahuan, menawarkan kesempatan kepada negara berkembang untuk meningkatkan sistem pendidikan, memperbaiki perumusan kebijakan dan pelaksanaannya, serta memperluas jangkauan peluang bagi masyarakat miskin atau terpencil (Tinio, 2003). Salah satu kesulitan terbesar yang dialami masyarakat miskin, dan orang lain yang tinggal di negara-negara tertinggal adalah rasa keterasingan. Internet berpeluang menguranginya dan membuka akses terhadap pengetahuan dengan cara yang luar biasa.

TIK untuk pendidikan yang dimanfaatkan optimal berpotensi meningkatkan lima hal berikut: 1) expanding access, 2) promoting efficiency, 3) improving the quality of learning, 4) enhancing the quality of teaching, dan 5) improving management system (Haddad \& Draxler, 2002; Tinio, 2003). Meski pada awalnya internet tidak dikembangkan untuk tujuan pendidikan, namun kini internet menjadi salah satu sarana peningkatan akses pendidikan, penyebaran konten edukasi, dan strategi peningkatan pendidikan lainnya (Bokova \& Touré, 2013). Integrasi pemanfaatan TIK dan internet untuk pendidikan dan kurikulum bertujuan agar value pendidikan menjadi lebih tepat sasaran, inovatif, dan transformatif (Shahmir dkk, 2010; Smaldino, 2011).

Data Balitbang Kemkominfo 2017 (https://statistik.kominfo.go.id/site/data) memaparkan bahwa mayoritas masyarakat Indonesia menggunakan internet untuk membuka situs jejaring sosial (73.30\%). Kemudian penelitian mengenai Lanskap Digital di Indonesia Tahun 2017 oleh organisasi We Are Social (2017) menunjukkan bahwa dengan total populasi mencapai 265.4 juta jiwa, Indonesia merupakan pasar pengguna internet yang potensial. Jumlah pengguna ponsel sebanyak 177.9 juta orang, sebanyak 132.7 juta orang merupakan pengguna internet, 130 juta orang aktif menggunakan sosial media, dan 120 juta orang menggunakan ponsel dalam bersosial media.

Pemanfaatan internet untuk pendidikan merupakan salah satu bentuk implementasi revolusi industri keempat yang cirinya antara lain teknologi digital dan interkoneksi keilmuan (Nordin \& Norman, 2017). UNESCO (2016) me- 
nyatakan bahwa teknologi revolusi industri keempat harus dimanfaatkan dengan prinsip pemerataan, kesetaraan, inklusi, dan membangun ketahanan atas dasar nilai bersama dan etika. Hal ini sangat relevan dengan program USO di sekolah 3T yang mengupayakan keadilan layanan sekaligus memperkuat ketahanan nasional melalui pendidikan di daerah garis depan.

Apakah pemanfaatan TIK dan internet untuk pendidikan di wilayah 3T sudah terlaksana dengan baik? Penelitian ini berupaya mengkaji sejauh mana TIK dimanfaatkan oleh guru di sekolah penerima USO. Ranah utilization sesuai dengan Domain of the Fields dalam Teknologi Pembelajaran (Seels \& Richey, 1994) dijadikan acuan mengkaji pemanfaatan. Menurut Seels and Richey, "utilization is the act of using processes and resources for learning; utilization concentrates on the learner; the interface between the learner and instructional materials and systems. Ranah pemanfaatan paling banyak berhubungan langsung dengan pengguna, kebijakan, aturan, dan standar yang berlaku.

Peneliti memilih guru sebagai objek kajian dalam pemanfaatan TIK. Karena walau paradigma pembelajaran kini berpusat pada peserta didik dan berubah menjadi proses transformasional, namun peran guru tetaplah vital (McBeath, 1994). Guru adalah bagian dari penye-lenggara pendidikan, partisipan pengem-bangan kurikulum, sekaligus implemen-tator utama kurikulum (Ornstein \& Hunkins, 2013; Theodorou, Philippou \& Kontovourki, 2017). Salah satu kualitas guru ditunjukkan dengan penguasaan empat kompetensi sesuai Undang-Undang No.14 Tahun 2005 tentang Guru dan Dosen. Kemampuan memanfaatkan TIK untuk pembelajaran melekat pada kompetensi pedagogik, profesional, sosial, dan kepribadian guru. Keterbatasan dan tantangan dalam mengajar di wilayah 3T tentu membuat tugas guru semakin berat. Mengingat betapa potensialnya TIK untuk pendidikan, dan krusialnya kemampuan guru dalam mendayagunakan TIK, maka penelitian untuk memperoleh gambaran pemanfaatan TIK oleh guru di sekolah USO tidak hanya menarik tapi juga penting untuk dilakukan.

\section{METODE}

Metode yang digunakan dalam penelitian adalah survei tipe cross-sectional, karena penyebaran instrumen untuk guru di sekolah USO dilaksanakan dalam satu waktu pengambilan data (Creswell, 2014; Ali, 2014). Pengumpulan data dengan instrumen berupa angket dilakukan selama Maret 2018 sesuai jadwal Monitoring dan Evaluasi periode pertama yang dilakukan salah satu instansi penyelenggara USO (Pustekkom Kemendikbud). Responden dalam penelitian ini adalah 141 orang guru yang tersusun atas:

Tabel 1. Sebaran Responden

\begin{tabular}{clc}
\hline No & \multicolumn{1}{c}{$\begin{array}{c}\text { Guru Tingkat } \\
\text { Sekolah }\end{array}$} & Jumlah \\
\hline 1 & Guru SD & 17 orang \\
2 & Guru SMP & 32 orang \\
3 & Guru SMA & 62 orang \\
4 & Guru SMK & 30 orang \\
\hline
\end{tabular}

Penetapan sampel penelitian dilakukan dengan menggunakan teknik penyampelan seadanya (Sudjana, 2013). Jumlah 141 orang responden berasal dari empat tingkatan sekolah diasumsikan mewakili populasi guru di sekolah penerima USO. Semua guru di sekolah penerima USO dianggap memiliki kriteria sama, peneliti hanya menunggu berapa pun jumlah angket yang kembali dalam jangka waktu yang telah ditentukan. Indikator yang ditanyakan dalam angket meliputi: 1) penggunaan alat bantu mengajar berbasis TIK, 2) pemanfaatan media sosial, 3) pengembangan konten pembelajaran berbasis TIK, 4) kompetensi TIK yang dimiliki, 5) akses web dan internet. Data angket kemudian diolah dan disajikan dalam bentuk persentase dan grafik. Selanjutnya data dianalisis secara deskriptif, yaitu dengan mendeskripsikan hasil yang diperoleh kemudian memaknainya (Creswell, 2015). 
Untuk memperkuat penelitian survei, dilakukan studi dokumentasi yang merupakan salah satu metode dalam pendekatan penelitian kualitatif (Creswell, 2014; Ali, 2014). Jenis dokumen yang dijadikan sumber data adalah: 1) catatan lapangan dari lokasi sekolah USO yang divisitasi oleh petugas Monitoring dan Evaluasi dari Pustekkom Kemdikbud pada Maret 2018, dan 2) desain penyelenggaraan program USO. Konten dalam dokumen yang ada kemudian dianalisis dan dideskripsikan maknanya (Bungin, 2005).

\section{HASIL DAN PEMBAHASAN Hasil}

Tabel 2. Perubahan Desain Program USO

\begin{tabular}{|c|c|c|}
\hline No & USO Sebelumnya & Redesign USO \\
\hline 1 & Koordinasi lemah, utilisasi rendah & $\begin{array}{l}\text { Menggunakan prinsip bottom up, } \\
\text { komprehensif, piloting, sinergi }\end{array}$ \\
\hline 2 & Hanya infrastruktur & $\begin{array}{l}\text { Dilengkapi ekosistem dan } \\
\text { pemberdayaan masyarakat }\end{array}$ \\
\hline 3 & Kontrak rigid & Kontrak sederhana melalui e-katalog \\
\hline 4 & Check and balance kurang akuntabel & Check and balance lebih akuntabel \\
\hline 5 & $\begin{array}{l}\text { Penyelesaian masalah kontrak existing } \\
\text { diselesaikan task force }\end{array}$ & $\begin{array}{l}\text { Redesign USO dilaksanakan dengan } \\
\text { struktur baru }\end{array}$ \\
\hline
\end{tabular}

\section{Implementasi Program USO}

Sejak digagas pada tahun 2015, jumlah sekolah yang memperoleh program akses internet USO terus bertambah. Berikut grafik jumlah sekolah penerima dan pengusul USO:

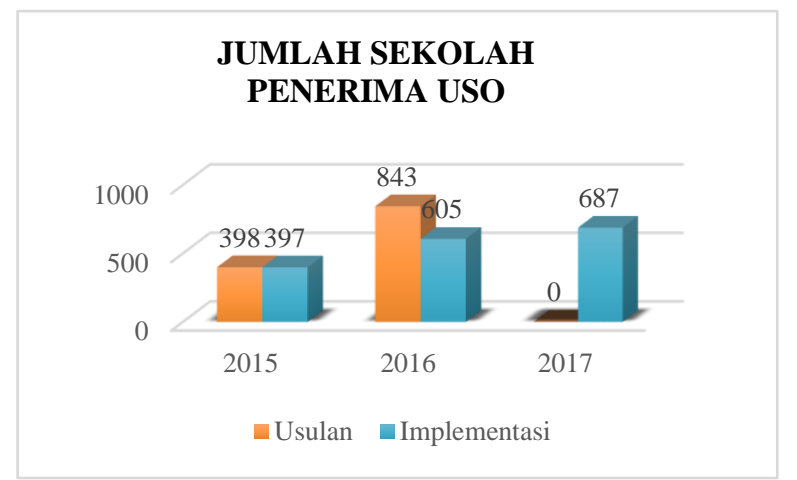

Gambar 1. Implementasi Program Akses Internet di Sekolah USO

Jumlah 687 sekolah yang dilayani program USO terdiri dari tingkat SD, SMP,
Dari isian angket 141 responden dan studi terhadap beberapa dokumen terkait, diperoleh hasil penelitian Pemanfaatan TIK oleh Guru di Sekolah Penerima USO sebagai berikut:

\section{Redesign Program USO}

Untuk meningkatkan pemanfaatan dan efektifitas bantuan layanan USO berupa BTS, akses internet, dan Desa Broadband, pada tahun 2017, penanggungjawab USO merumuskan skema baru rancangan dengan merevisi beberapa aspek dari rancangan lama tahun 2015, yaitu:
SMA, dan SMK yang tersebar di berbagai kabupaten kategori 3T di 33 propinsi seluruh Indonesia (kecuali propinsi DKI Jakarta). Jumlah dalam grafik tersebut bersifat akumulatif setiap tahunnya.

\section{Bantuan Akses Internet Sekolah}

Besaran bandwidth yang diberikan kepada masing-masing sekolah USO bervariasi antara $512 \mathrm{Kbps}, 1024 \mathrm{Kbps}$, dan 2048 Kbps. Bandwidth ini bersifat dinamis, yakni besaran bandwidth bisa dinaikkan atau diturunkan sesuai dengan frekuensi pemakaian. Monitoring jaringan dilakukan dengan menggunakan Network Monitoring System (NMS) terhadap titik akses sekolah. Jika dalam 3 bulan uptime dan akses pemanfaatan sangat rendah, maka besaran bandwidth akan diturunkan. Besaran bandwidth secara default adalah 2048 Kbps. Berikut hasil evaluasi kapasitas bandwidth sesuai kontrak: 


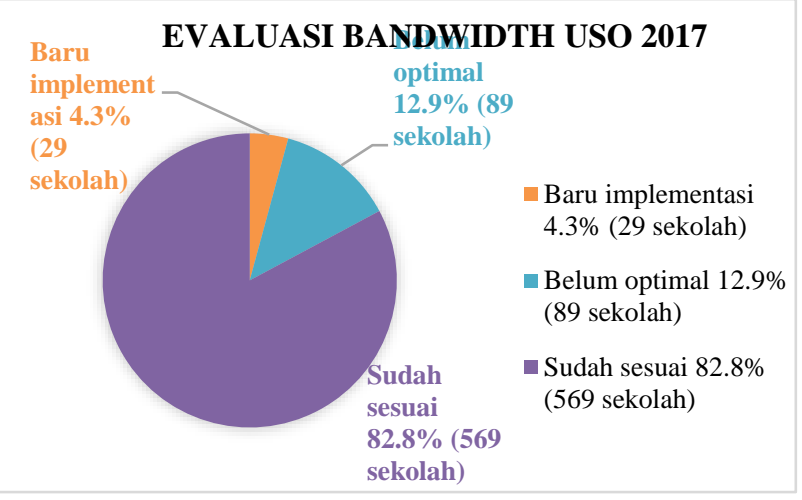

Gambar 2. Evaluasi Kesesuaian Kontrak Bandwidth untuk Sekolah USO

Ada tiga jenis media untuk akses internet di sekolah USO, yakni VSAT (Parabola), Serat Optik (Fiber Optic/FO), dan Nirkabel (Wireless). Untuk pembangunan nasional dengan prioritas dari wilayah perbatasan atau pinggiran, mayoritas sekolah USO menggunakan media VSAT. Karena kondisi wilayah 3T memang belum banyak terhubung dengan jalur FO atau sinyal 3G/4G. Berikut ini grafiknya:

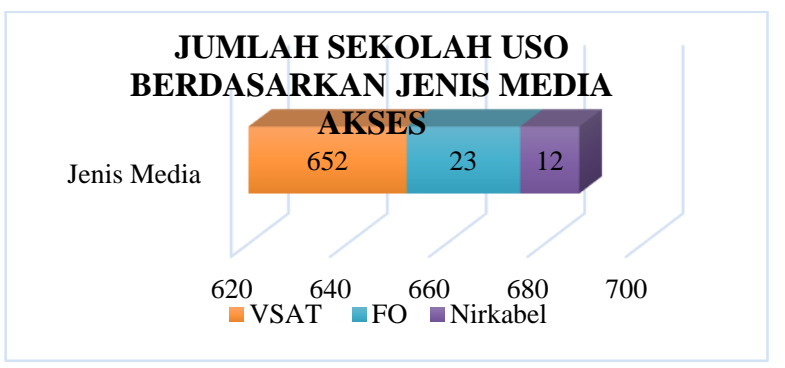

Gambar 3. Jumlah Sekolah dan Jenis Media

\section{Hasil Survei Pemanfaatan TIK}

Rekapitulasi data hasil angket yang diperoleh dari 141 responden guru dalam memanfaatkan TIK dan internet di sekolah penerima USO adalah sebagai berikut:

\section{Alat Bantu Mengajar Berbasis TIK}

Sebanyak 117 responden (82.9\%) menjawab sudah menggunakan alat bantu mengajar berbasis TIK, sedangkan sisanya 24 responden (17.1\%) menjawab belum menggunakan. Selanjutnya jenis alat bantu mengajar berbasis TIK dari 117 responden tersusun atas 3 kategori yaitu:

- 104 responden (88.9\%) menggunakan jenis offline seperti ekspositori ditambah dengan media audio, film, $e$-book

- 8 responden (6.8\%) menggunakan jenis hybrid seperti penggunaan media sosial atau surel untuk pembelajaran

- 5 responden (4.3\%) menggunakan jenis online seperti penggunaan learning management system.

\section{Media Komunikasi yang Digunakan}

Komunikasi antara guru dengan peserta didik merupakan hakikat pembelajaran. Gambaran pemanfaatan media komunikasi berbasis TIK oleh responden guru di sekolah penerima USO adalah:

Tabel 3. Jenis Media Komunikasi Guru

\begin{tabular}{|c|c|c|c|}
\hline Blog & Pos-el & Facebook & Lainnya \\
\hline $\begin{array}{c}15 \text { responden } \\
\text { memiliki } \\
\text { Blog }(10.6 \%)\end{array}$ & $\begin{array}{c}59 \text { responden } \\
\text { memiliki } \\
\text { Pos-el } \\
(41.8 \%)\end{array}$ & $\begin{array}{c}71 \text { responden } \\
\text { memiliki } \\
\text { Facebook } \\
(50.4 \%)\end{array}$ & $\begin{array}{c}44 \text { reponden }(31.2 \%) \\
\text { menjawab beragam } \\
\text { media lain, mayoritas } \\
\text { Whatsapp, lalu ada Kelas } \\
\text { Maya, kelase.net, } \\
\text { Edmodo, sosial media } \\
\text { dan SMS }\end{array}$ \\
\hline
\end{tabular}

Jenis Konten Pembelajaran yang Dibuat Guru yang profesional dan kompeten secara pedagogik tentu mampu memanfaatkan beragam media pembelajaran, bahkan mengembangkan sendiri media atau bahan ajar sesuai kebutuhannya, termasuk yang berbasis TIK. Berikut rekapitulasi jumlah konten pembelajaran yang dimiliki responden, berdasarkan jenis kontennya 
Tabel 4. Konten Pembelajaran yang Dimiliki Guru

\begin{tabular}{ccccc}
\hline & $\begin{array}{c}\text { Teks (PPT, } \\
\text { buku, } \\
\text { modul) }\end{array}$ & $\begin{array}{c}\text { Animasi } \\
\text { Multi- } \\
\text { media }\end{array}$ & $\begin{array}{c}\text { Simulasi } \\
\text { Multi- } \\
\text { media }\end{array}$ & $\begin{array}{c}\text { Video } \\
\text { Pemb. }\end{array}$ \\
\hline Tidak memiliki & 35 orang & 72 orang & 72 orang & 46 orang \\
Memiliki & 106 orang & 69 orang & 69 orang & 95 orang \\
Jumlah konten & 724 konten & 325 konten & 234 konten & 546 konten \\
Rata-rata konten & 6.8 konten & 4.7 konten & 3.4 konten & 5.7 konten \\
\hline
\end{tabular}

Data pada Tabel 4 hanya merekap jumlah konten yang dimiliki guru. Angket tidak menanyakan konten yang dimiliki/ digunakan merupakan bahan ajar yang dikembangkan sendiri, atau memanfaatkan konten pada bahan ajar yang sudah tersedia tanpa mengembangkan sendiri. Dari jenis konten yang ditanyakan, terlihat bahwa teks, animasi, simulasi, dan video pembelajaran termasuk ke dalam jenis media pembelajaran by design.

\section{Kompetensi TIK Guru Sekolah USO}

Kompetensi TIK perlu dimiliki oleh guru karena dapat memberi dampak positif bagi guru sendiri, untuk meningkatkan core business pendidikan maupun bagi supporting system. Berikut ini jawaban 141 responden mengenai kompetensi TIK yang dimiliki sebagai guru:

\section{Kompetensi TIK Guru}

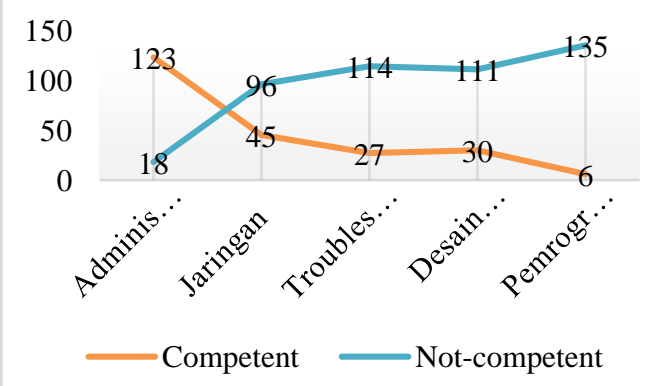

Gambar 4. Kompetensi TIK Guru di Sekolah USO

Kriteria masing-masing kompetensi TIK pada Gambar 4 sesuai yang ditanyakan dalam angket adalah sebagai berikut:

- Administrasi perkantoran: menguasai penggunaan aplikasi pengolah kata, spreadsheet, dan media presentasi
- Jaringan komputer dasar: memiliki kemampuan instalasi LAN/WLAN dan konsep jaringan

- Troubleshooting komputer: menguasai cara mengatasi masalah sistem operasi, aplikasi komputer, dan perangkat keras

- Desain grafis: memiliki kemampuan mengembangkan bahan ajar dengan menggunakan aplikasi grafis seperti Coreldraw, Macromedia Flash, dan lainlain.

- Pemrograman komputer: menguasai bahasa pemrograman komputer misalnya PHP, Java, Foxfro, Visual Basic, dan lainlain.
Akses Portal/Web oleh Guru
Dengan adanya akses internet dari program USO untuk sekolah, maka kesempatan bagi guru makin terbuka untuk mengakses beragam situs pendidikan dan pembelajaran. Hasil angket 141 responden mengenai situs portal/web pendidikan yang paling sering diakses dari sekolah USO adalah 56 responden $(39.7 \%)$ tidak mengisi jawaban. Sedangkan 85 responden $(60.3 \%)$ menjawab sering membuka situs web/portal berikut: 
Tabel 5. Situs Web/Portal yang Sering Diakses Guru

\begin{tabular}{lc}
\hline Situs Web/Portal Pendidikan & $\begin{array}{c}\text { Responden } \\
\text { yang } \\
\text { Mengakses }\end{array}$ \\
\hline Rumah Belajar & 29 \\
\hline Google & 14 \\
\hline Buku Sekolah Elektronik & 12 \\
\hline Youtube & 10 \\
\hline Materi ajar & 7 \\
\hline Blog Guru & 5 \\
\hline Yahoo & 4 \\
\hline Ilmukomputer, Wikipedia, Email, \\
$\begin{array}{l}\text { Facebook (masing-masing dijawab } \\
\text { oleh 3 responden) }\end{array}$ & 3 \\
\hline $\begin{array}{l}\text { KBBI Daring, Ruang Guru, SIM } \\
\text { PKB Guru, Dapodik (masing- } \\
\text { masing dijawab oleh 2 responden) }\end{array}$ & 2 \\
\hline $\begin{array}{l}\text { TV Edukasi, BOS Online, DJP } \\
\text { Online, Brainly.co.id, Gramedia } \\
\text { (masing-masing dijawab oleh 1 } \\
\text { responden) }\end{array}$ & 1 \\
\hline
\end{tabular}

Data jawaban responden pada Tabel 5 tidak menyebutkan persentase karena dari 85 responden yang menjawab, banyak di antaranya yang mengisi lebih dari satu situs web/portal. Angket juga menanyakan beberapa situs pembelajaran resmi milik Kemendikbud (domain kemdikbud.go.id) yang diketahui oleh guru di sekolah USO. Hasil angket 141 responden adalah sebagai berikut:

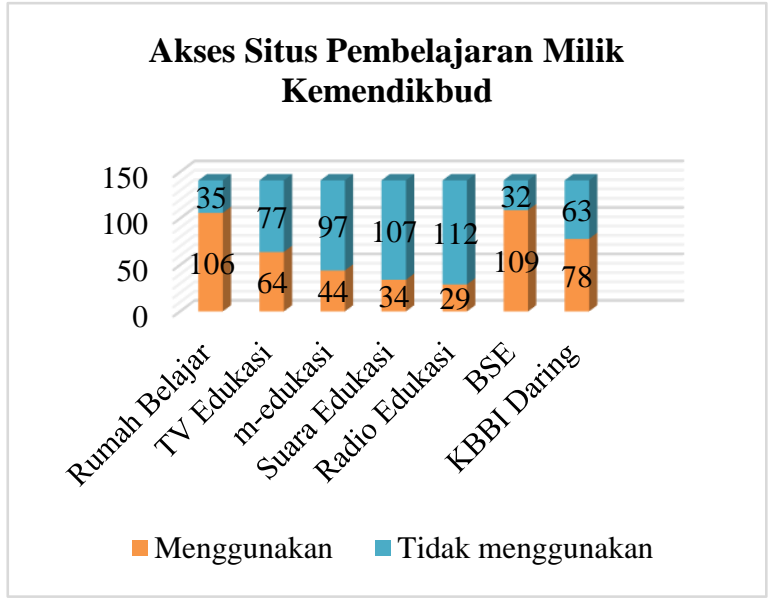

Gambar 5. Akses Situs Pembelajaran oleh Guru di Sekolah USO

\section{Pembahasan}

Program bantuan layanan TIK untuk sekolah di wilayah $3 \mathrm{~T}$ dalam bentuk akses internet USO sudah berlangsung sejak
2015, yang artinya memasuki tahun keempat di tahun 2018 ini. Pendayagunaan TIK dalam program USO diarahkan untuk mendukung pencapaian pendidikan berkualitas dan berkelanjutan, menghadapi persaingan global dan cepatnya arus informasi. Integrasi TIK (termasuk internet) dalam pendidikan dapat ditinjau dari beberapa aspek, yaitu: TIK sebagai alat untuk membantu proses, sebagai konten untuk dipelajari, dan sebagai bagian dari sistem pembelajaran (Somekh, 2007; Sutherland, Robertson, \& John, 2009; Shahmir dkk, 2010). Kemudian Pelgrum (2001) menyebutkan perlunya peran pemerintah dalam integrasi TIK untuk pendidikan. Penelitian lain (Hearne, 2002; Tondeur, Braak, \& Valcke, 2007; McGarr, 2009) memperkuat dengan pernyataan bahwa diperlukan peran pemerintah dalam menentukan kerangka kerja TIK, sehingga pelaksana kurikulum di sekolah tidak mengalami kebingungan untuk mengintegrasikan TIK.

Untuk mengkaji pemanfaatan akses internet oleh guru di sekolah USO, peneliti tidak hanya mensurvei respon dari pihak guru sebagai pengguna. TIK yang ada dalam sistem pendidikan akan berdampak sistemik pula. Sehingga kajian pemanfaatan pun ditinjau dari sudut pandang sistemik. Teori yang digunakan adalah sistem ranah dalam Instructional Technology yang dikenal dengan Domain of the Fields oleh Seels \& Richey (1994), terdiri atas ranah Desain, Pengembangan, Utilisasi, Pengelolaan, dan Evaluasi. Seels \& Richey menyebutkan bahwa semua ranah dan subkategorinya harus saling berkaitan, melengkapi, dan sinergis agar keseluruhan sistem berlangsung dengan baik. Lebih spesifik lagi, teori fokus pada subkategori ranah utilisasi, yaitu 1) pemanfaatan media, 2) difusi inovasi, 3) implementasi dan institusionalisasi, serta 4) kebijakan dan regulasi.

Penelitian juga mengacu teori model ADDIE yang merupakan akronim dari setiap fase yang menyusun pengembangan sebuah sistem, yaitu Analysis, Design, Development, Implementation, 
dan Evaluation. Model ini tidak asing dalam Instructional Design maupun Instructional Technology (Molenda, 2003). Model ADDIE dijadikan acuan sistemik untuk meneliti integrasi TIK dalam pendidikan di sekolah USO. Dalam model ADDIE disebutkan bahwa semua fase harus saling terkait dan berpengaruh. Pemanfaatan TIK termasuk ke dalam fase implementasi. Maka dengan mengacu pada ranah utilisasi dan model ADDIE, serta berdasarkan data-data yang diper-oleh dari beberapa sumber, kajian pemanfaatan TIK oleh guru di sekolah penerima USO dapat dianalisis dan dideskripsikan ke dalam ke beberapa sub bahasan. Aspek-aspek yang berpengaruh pada proses pemanfaatan TIK (khususnya akses internet) oleh guru juga dikaji dan dideskripsikan.

\section{Perencanaan Program USO}

Gagasan besar program USO adalah kewajiban pemberian layanan bidang telekomunikasi dan informatika bagi publik yang tujuan utamanya untuk mengurangi kesenjangan digital di daerah khususnya pedesaan, tertinggal, dan terluar, yang secara ekonomi sulit dilakukan oleh penyelenggara telekomunikasi komersial. Program layanan USO yang telah berlangsung diawali dengan layanan dasar (voice) hingga layanan data (internet). Layanan USO bergerak dengan menggandeng berbagai bidang seperti perdagangan hingga pendidikan. Sesuai dengan bidang layanan program USO yakni telekomunikasi dan informatika serta perkembangan teknologi yang tengah memasuki revolusi industri keempat, maka merupakan hal yang lumrah bila terjadi fusi antara kedua hal tersebut. TIK adalah solusi yang dipilih.

Pemanfaatan teknologi dalam proses pengelolaan informasi dan proses komunikasi menghasilkan fusi yang disebut dengan TIK. Pengertian TIK menurut Tinio (2003) adalah diverse set of technological tools and resources used to communicate, and to create, disseminate, store, and manage information. Kemudian, Haydn (2004) dalam penelitiannya mengutip definisi TIK menurut The Teacher Training Agency (TTA) yaitu beragam teknologi yang dapat digunakan untuk mengkomunikasikan informasi, meliputi komputer, internet, $C D-R O M$ dan software lainnya, televisi, radio, kamera, dan sebagainya. Pemanfaatan TIK dalam artikel ini fokus pada penggunaan akses internet oleh guru di sekolah penerima program USO. Sasaran USO adalah memberikan layanan TIK untuk pendidi-kan di wilayah 3T yang menjadi prioritas pembangunan sekaligus memperkuat keta-hanan nasional dari daerah pinggiran.

Sesuai dengan kaidah sistemik, sebelum implementasi program dilakukan dan dimanfaatkan, tentu harus melalui tahap analisis. Berdasarkan kajian dokumen program yang telah berjalan, diketahui bahwa tidak dapat disangkal jika program USO untuk pendidikan mem-butuhkan anggaran biaya yang amat besar. Selain skema pembiayaan, perencanaan program yang perlu dipersiapkan agar program gelaran akses internet dapat berjalan dan bermanfaat, berikut ini analisis hingga perancangan sistem yang dilakukan oleh penyelenggara program:

1) Analisis kebutuhan pendidikan di lapangan yang dapat difasilitasi oleh adanya internet

2) Mempersiapkan infrastruktur dasar dan pendukung yang tepat untuk karakteristik wilayah $3 \mathrm{~T}$

3) Rancangan besar dan sistemik termasuk Prosedur Operasional Sistem (POS) untuk beragam standar layanan TIK untuk program USO untuk pendidikan di wilayah $3 \mathrm{~T}$

4) Desain pemanfaatan yang tepat berisi layanan-layanan pendidikan yang dapat ditingkatkan melalui pemanfaatan internet di sekolah USO. Pemanfaatan internet di sekolah harus mencakup bidang core business (misalnya e-pembelajaran) maupun supporting system pendidikan (misalnya e-administrasi).

5) Penguatan SDM pendidikan di wilayah 3T terkait pengelolaan dan pemanfaatan yang benar serta efektif. 
Penguatan SDM meliputi lingkup manajemen, teknis, pembelajaran, hingga masyarakat dan komunitas.

6) Pengelolaan (perencanaan pengorganisasian, koordinasi, dan supervisi) keseluruhan sistem mencakup SDM dan sumber daya lainnya, sistem penyampaian, dan pengelolaan informasi.

7) Evaluasi dan keberlanjutan (sustainability) program USO.

\section{Kebijakan Program}

Untuk mendukung keberlangsungannya, sebuah program harus didukung kebijakan dan regulasi yang tepat. Demikian pula dengan program USO sebagai layanan TIK pendidikan. Kebijakan penyelenggaraan dan penguatan akses internet untuk sekolah di wilayah 3T berawal dari gagasan pemerintah. Artinya kebijakan bersifat top down. Kebijakan program USO bukan hanya kebijakan teknis mengenai infrastruktur seperti pengadaan, namun juga melibatkan kebijakan pendidikan.

Sifat kebijakan pendidikan harus mempertimbangkan dan mencerminkan konteks geografis, demografi, ekonomi, sosial, budaya, dan politik suatu negara (UNESCO, 2013). Konteks kebijakan pendidikan untuk wilayah 3T harus mewakili segala macam kekhasan dan tantangan yang ada di wilayah tersebut. Kebijakan top down program USO menjadi titik awal pengembangan pendidikan dengan memanfaatkan TIK yang harus ditindaklanjuti dengan penentuan strategi yang tepat, kemudian disusul dengan perumusan rencana integrasi TIK dengan pendidikan melalui USO yang lebih spesifik, misalnya:

1) Menyusun raod map integrasi pemanfaatan internet untuk pembelajaran dan administrasi pendidikan di wilayah $3 \mathrm{~T}$

2) Menetapkan target dan output spesifik

3) Mengidentifikasi sumber daya yang dibutuhkan serta pengelolaan yang tepat agar selalu melayani kebutuhan di wilayah dengan karaketeristik khusus tersebut

4) Menentukan batasan waktu capaian target yang justru menjadi pemacu untuk meraih keberlanjutan program (sustainability).

Jadi, sinergitas antara kebijakan dari pusat dengan implementasi program USO di daerah harus diakomodir dengan strategi dan perencanaan yang terkoordinasi dengan baik. Dengan mencermati Tabel 2 diketahui bahwa kebijakan program USO mengalami revisi. Bila sebelumnya top down sangat dominan, maka selanjutnya sifat bottom up lebih diutamakan. Hal ini ditengarai dari hasil monitoring dan evaluasi tahun sebelumnya bahwa pemanfaatan internet di sejumlah sekolah masih rendah. Maka untuk meningkatkan efektifitas peman-faatan, prioritas program bergeser pada sekolah yang mengusulkan, karena lebih berdasarkan pada kebutuhan lokal dan masyarakat. Upaya peningkatan layanan program USO supaya lebih bermanfaat dilakukan secara komprehensif melibat-kan ekosistem sekolah, misalnya pember-dayaan komunitas lokal untuk mengisi konten pembelajaran berbasis TIK. Tidak hanya mengagendakan gelaran infra-struktur TIK, program USO juga mengarah pada piloting, memberikan dukukan pada sekolah dan daerah yang siap memanfaatkan TIK. Serta meningkatkan proses pengawasan untuk menjaga kesinambungan program bagi stake holders, sejak tahap perencanaan, pelaksanaan, hingga evaluasi.

\section{Proses Implementasi}

Apabila tahap analisis, perencanaan, dan perancangan telah disusun dan didukung dengan kebijakan yang sesuai, maka idealnya tahap implementasi dan pemanfaatan, akan berlangsung dengan baik. Untuk program USO yang telah diimplementasikan hingga saat ini diketahui perbaikan layanan terus dilakukan. Sesuai dengan aspek dalam ranah utilisasi, kebijakan dan regulasi 
mempengaruhi pelaksanaan program layanan USO.

Sebagaimana diketahui dari Gambar 1 sebenarnya kebijakan implementasi program USO sudah memiliki semangat bottom up, dengan menampung usulan dari pihak dinas pendidikan daerah mengenai sekolah di wilayah 3T yang layak menerima bantuan program USO. Meskipun pada prakteknya kebijakan top down lebih mendominasi pelaksanaan program USO. Penentuan sekolah yang memperoleh bantuan TIK berupa akses internet lebih dominan bersifat keputusan pusat. Perubahan formulasi kebijakan pada tahun 2017 kini mengutamakan usulan bottom up supaya kebermanfaatan akses internet lebih tepat sasaran dan sesuai kebutuhan di lapangan. Perubahan kebijakan menunjukkan bahwa: meskipun kebijakan bersifat terpusat, namun karena yang melaksanakan adalah level daerah, maka kebijakan harus fleksibel untuk mengakomodir kebutuhan implementator dan stakeholders. Kebijakan pendidikan, in a particular stance, aiming to explore solutions to an issue (UNESCO, 2013). Contoh lain adalah penerapan kebijakan untuk besaran bandwidth yang pada akhirnya diberikan secara dinamis. Hal ini bertujuan untuk memotivasi penggunaan internet yang lebih optimal untuk pendidikan.

Di dalam tahap utilisasi ada pula faktor pemanfaatan jenis media ataupun teknologi yang sifatnya meningkatkan fungsi dan proses. Seels \& Richey (1994) menyebutkan difusi dan inovasi sebagai salah satu determinan dalam tahap utilisasi. TIK, khususnya akses internet dalam program USO adalah media yang dimaksud dalam ranah utilisasi. Akses internet yang dimanfaatkan dengan baik tentu telah melewati tahap penerimaan sebagai inovasi dan digunakan karena sesuai dengan kebutuhan. Penerimaan pengguna akan akses internet sebagai media sekaligus difusi inovasi terkait erat dengan kepuasan pengguna (user satisfaction).
Fase implementasi model ADDIE yang diterapkan dalam pendidikan dan pembelajaran fokus pada isu sistem penyampaian (delivery system) yang akan mempengaruhi proses maupun hasil. Pada pelaksanaan program layanan USO, sistem penyampaian dapat diasosiasikan dengan jenis media atau teknologi yang dipilih. Sebagaimana yang ditampilkan pada Gambar 3 yakni sekolah penerima USO dibedakan atas akses VSAT, FO, dan Nirkabel. Perbedaan dan kekhasan kondisi wilayah 3T menyebabkan tiga jenis teknologi tersebut dipilih dalam memberikan layanan akses internet. Selain terkait dengan alat, sistem penyampaian pun dapat berupa program. Untuk pelaksanaan program USO di sekolah, supaya pemanfaatan TIK di sekolah tercapai sesuai tujuan, maka diperlukan program yang sesuai dan sistemik. Pelibatan berbagai komponen sekolah berguna untuk mendukung dan mengoptimalkan pemanfaatan TIK di sekolah. Meskipun guru adalah implementator utama kurikulum sekaligus motor penggerak pembelajaran, SDM lain di sekolah akan saling terkait dalam memberikan layanan pembelajaran kepada peserta didik. Sesuai dengan aturan pemerintah, TIK tidak lagi berdiri sebagai mata pelajaran tersendiri bukan karena dianggap tidak penting melainkan dapat dipelajari atau diaplikasikan dalam bentuk aktivitas belajar lain. Kompetensi TIK dapat dikuasai dengan beragam cara.

Literasi TIK di sekolah bukan hanya tanggung jawab guru. Manajemen sekolah perlu mengkoordinasikan pelibatan SDM, dan sumber daya lainnya termasuk biaya serta program-program sekolah. Dari sisi penanggungjawab layanan, sosialisasi dan pendampingan menjadi keharusan agar implementasi program lebih efektif. Inisiatif pemanfaatan TIK dan internet di sekolah harus senantiasa digagas, misalnya program peningkatan kompe-tensi TIK untuk guru, tendik, hingga masyarakat dan komunitas. Usulan aktif dari tataran grassroots menunjukkan apresiasi pemanfaatan TIK yang baik, dan tidak 
mustahil berdampak pada level lebih tinggi. Pada jurnal yang ditulisnya, Warsihna (2013) menyimpulkan bahwa keberhasilan implementasi TIK untuk pendidikan di wilayah $3 \mathrm{~T}$ sangat dipengaruhi oleh penerapan lima prinsip, yakni: 1) pemberdayaan, 2) bottom up, 3) sustainability, 4) pendekatan pembelajaran modern, dan 5) kemitraan.

\section{Hasil Penelitian dan Kebermanfaatan}

Sebagai SDM utama dalam core business pendidikan, guru dipilih sebagai responden kajian pemanfaatan TIK di sekolah penerima USO. Peneliti menyadari bahwa jumlah 141 responden tidak cukup mewakili banyaknya guru yang ada di sekolah penerima USO. Maka peneliti tidak melakukan generalisasi, hanya memaparkan gambaran peman-faatan TIK oleh guru di sekolah USO sesuai data yang diperoleh dari 141 responden.

Mayoritas responden (sebesar $82.9 \%$ ) menyatakan sudah menggunakan TIK sebagai alat bantu dalam pembelajaran. Meskipun baru sebagian kecil dari responden pengguna TIK yang memanfaatkan TIK berbasis daring. Sejalan dengan pesatnya perkembangan TIK dan semakin terbukanya akses, penggunaan media komunikasi serta sosial media, guru pun memanfaatkannya. Sebagian besar aktivitas penggunaan internet di Indonesia adalah untuk sosial media dan komunikasi teks (chatting), maka hal ini pun terjadi di wilayah $3 \mathrm{~T}$. Penggunaan media sosial dan sarana komunikasi yang cukup populer adalah Facebook dan artinya kepemilikan pos elektronik (e-mail) adalah hal yang lazim.

Pentingnya memanfaatkan TIK dalam pembelajaran disebutkan dalam Permendikbud No.81A Tahun 2013 tentang Implementasi Kurikulum. TIK menjadi bagian dari strategi pembelajaran. Salah satu bentuk yang paling umum adalah penggunaan bahan belajar berbasis TIK oleh guru. Dari jawaban 141 responden mengenai konten pembelajaran berbasis TIK di Tabel 4, diketahui bahwa bahan belajar yang paling banyak dimiliki guru adalah tipe paparan untuk membantu metode ekspositori. Jenis bahan belajar berbasis TIK lainnya, yang lebih interaktif dan dapat digunakan untuk belajar mandiri seperti animasi, simulasi atau video pembelajaran juga makin berkem-bang pemanfaatannya. Adanya akses internet di sekolah memperluas kesem-patan untuk mengeksplorasi aneka sumber belajar. Berdasarkan hal ini, diasumsikan bahwa implementasi program layanan TIK di sekolah USO meningkatkan akses global terhadap beragam sumber belajar berupa Open Education Resources (OERs).

TIK terus berkembang, baik berupa hardware maupun software. Hal ini perlu diimbangi dengan peningkatan brainware atau kemampuan pengguna. Tidak hanya terampil secara teknis, namun juga bijaksana dalam menggunakan TIK. Berdasarkan hasil angket yang ditampilkan pada Gambar 4, mayoritas dari 141 responden memiliki kompetensi TIK yang cukup baik. Kemampuan TIK yang paling banyak dikuasai adalah pengunaan TIK untuk administrasi perkantoran seperti pengolah kata dan presentasi. Sedangkan kemampuan TIK yang lebih spesifik seperti kemampuan jaringan komputer dasar, troubleshooting, desain grafis, dan pemrograman tidak terlalu banyak guru yang kompeten. Hal ini menunjukkan bahwa kompetensi TIK guru di wilayah 3 T atau sekolah penerima USO perlu terus ditingkatkan. Bentuk peningkatan kompetensi TIK yang paling lazim adalah pelatihan. Kemampuan teknis TIK biasanya tidak terlalu dianggap penting oleh guru mata pelajaran karena dirasa tidak berdampak langsung untuk keperluan mengajar. Namun sesuai dengan kebutuhan zaman bahwa mengajar tidak sekadar menyam-paikan materi pelajaran, maka guru pun harus terus belajar agar kompetensinya sesuai dengan kondisi lokal hingga global. Kolaborasi antar SDM pendidikan sema-kin diperlukan agar pencapaian tujuan sistemik pendidikan lebih efektif.

Peningkatan kompetensi TIK guru, tendik, dan SDM pendidikan lainnya 
merupakan sebuah kebutuhan, dan dengan sendirinya akan berdampak pada pemanfaatan TIK di sekolah. Untuk wilayah 3T, kompetensi TIK pada SDM pendidikan tidak hanya bermanfaat untuk bidang pendidikan, namun bisa memberi efek lingkup nasional. Pembangunan pendidikan dari wilayah garda depan bertujuan untuk mewujudkan ketahanan nasional. Berbagai layanan pendidikan dan administrasi kini banyak memanfaatkan basis daring, oleh karena itu pemanfaatan internet harus semakin meningkat dan merata terutama dari wilayah $3 \mathrm{~T}$ yang tantangannya lebih kompleks dari wilayah lainnya di Indonesia. Kemendikbud selaku penanggungjawab penyeleng-garaan pendidikan nasional tentu saja mengembangkan layanan pembelajaran maupun administrasi pendidikan berbasis TIK untuk dimanfaatkan seluas-luasnya bagi pendidikan nasional. Beberapa layanan daring berbasis web ditanyakan dalam angket. Hasil Tabel 5 dan Gambar 5 memberikan sedikit gambaran pemanfaatan layanan web-based Kemendikbud. Cukup banyak responden yang mengetahui dan memanfaatkan layanan TIK pendidikan tersebut. Apabila layanan TIK berbasis web yang ada terus ditingkatkan dan disosialisasikan dengan baik, maka diasumsikan penyebarannya akan lebih luas. Bahkan bisa memberikan dampak berupa peningkatan pemanfaatan TIK dan internet di sekolah termasuk wilayah $3 \mathrm{~T}$ yang menerima layanan USO.

\section{PENUTUP}

Pemanfaatan TIK oleh guru di sekolah penerima USO tidak hanya memberikan gambaran keberhasilan penyelenggara program USO. Dengan sudut pandang sistemik yang digunakan, akan tampak berbagai aspek yang mempengaruhi pemanfaatan TIK oleh guru di sekolah. Kondisi sekolah penerima USO yang termasuk wilayah 3T dengan karakteristik dan tantangan yang dihadapi tentu menjadi salah satu faktor yang mempengaruhi. Sebelum mengkaji pemanfaatan TIK yang termasuk dalam ranah implementasi atau utilisasi, ranah analisis, perancangan, dan pengembangan program pun perlu ditelaah untuk mengetahui apabila terjadi kesenjangan antara perencanaan dengan praktek implementasi.

Berdasarkan hasil survei terhadap guru sekolah penerima USO, pemanfaatan TIK dan internet untuk pembelajaran sudah cukup baik. Internet tidak lagi dianggap sebagai teknologi yang terlalu rigid, karena memang sudah menyentuh tingkat kebutuhan guru. Dukungan sistemik juga diperlukan guru dalam memanfaatkan TIK yang terintegrasi dengan kurikulum. Pemanfaatan TIK di sekolah akan lebih efektif apabila sekolah melakukan pelibatan sekuruh komponen pendidikan termasuk manajemen sekolah, guru dan tendik, hingga masyarakat dan komunitas. Tingginya frekuensi pemanfaatan internet untuk pendidikan oleh guru di wilayah 3T menjadi salah satu tujuan program layanan USO yang ditetapkan oleh penyelenggara layanan. Pemanfaatan TIK oleh guru terkait dengan kemampuan atau kompetensi guru. Harapannya, dengan kompetensi TIK yang baik maka pemanfaatan TIK akan lebih berkembang. Maka, supaya pemanfaatan TIK oleh guru menjadi makin efektif sebaiknya program layanan TIK USO menyelaraskan antara bantuan teknis/perangkat dengan program pening-katan kompetensi TIK guru dan SDM pendidikan lainnya.

Penelitian ini masih memiliki banyak keterbatasan, misalnya terlalu kecilnya jumlah sampel atau kurangnya perspektif kajian. Oleh karena itu, tidak menutup kemungkinan untuk diteliti lebih jauh, dengan data yang lebih besar atau aspek kajian yang lebih tajam dan bera-gam.

\section{UCAPAN TERIMA KASIH}

Peneliti mengucapkan terimakasih kepada pimpinan dan staf Pustekkom Kemendikbud, khususnya di bidang Pengembangan Jejaring, atas akses data yang diberikan. 
DAFTAR PUSTAKA

Ali, M. (2014). Memahami riset perilaku dan sosial. Jakarta: Bumi Aksara.

BPS - Badan Pusat Statistik. (2017). Potret pendidikan Indonesia - statistik pendidikan 2017. Jakarta: Badan Pusat Statistik.

BSNP - Badan Standar Nasional Pendidikan. (2010). Paradigma pendidikan nasional abad xxi. Jakarta: Badan Standar Nasional Pendidikan.

Bokova, I. and Touré, H.I. (2013). Technology, broadband, and education - advancing the education for all agenda. Paris: UNESCO.

Bungin, B. (2005). Analisis data penelitian kualitatif: Pemahaman filosofis dan metodologis ke arah penguasaan model aplikasi. Jakarta: Raja Grafindo Persada.

Carnoy, M. (1999). Globalization and educational reform: What planners need to know. Retrieved from http://unesco.amu.edu.pl/pdf/Carnoy. pdf.

Creswell, J.W. (2014). Research design pendekatan metode kualitatif, kuantitatif, dan campuran, edisi 4. Yogyakarta: Pustaka Pelajar.

Creswell, J.W. (2015). Riset pendidikan perencanaan, pelaksanaan, dan evaluasi riset kualitatif \& kuantitatif. Yogyakarta: Pustaka Pelajar.

Data dan Statistik Kementerian Komunikasi \& Informatika RI. (2017). Aktivitas menggunakan internet oleh individu pada tahun 2016. Retrieve from https://statistik.kominfo.go.id/site/dat a? idtree $=424 \&$ iddoc $=1521$.

Galli, A., Durovic, G., Hanscom, L., \& Knezevic, J. (2018). Think globally, act locally: Implementing the sustainable development goals in Montenegro. Enviromental Science and Policy, 84(2018), 159-169. doi: https://doi.org/10.1016/j.envsci.2018 .03.012.

Haddad, W.D. and Draxler, A. (2002). Technology for education potentials, parameters, and prospect. Paris and Washington DC: UNESCO and Academy for Educational Development.

Haydn, T.A. (2004). The use of the information and communication technology in history teaching in secondary schools in England and Wales 1970-2003. (Thesis of Doctor of Philosophy). Institute of Education, University of London, London.

Hearne, U. (2002). Changing the culture of a primary school: The case of introducing ICT across the curriculum. Irish Educational Studies, 21(2), 65-75.

Hudson, M. (2010). Think globally, act locally: collective consent and the ethics of knowledge production. International Social Science Journal, 60(195). 125-133. doi: https://doi.org/10.1111/j.14682451.2009.01706.x.

McBeath, R.J. (1994). The impact of paradigm shift on education. Educational Media International, 31:3, 165-170.

McGarr, O. (2009). The development of ICT across the curriculum in Irish schools: A historical perspective. British Journal of Educational Technology, 40(6), 1094-1108.

Molenda, M. (2003). In search of the elusive ADDIE model. Performance Improvement, 42(5), 34-36. doi: https://doi.org/10.1002/pfi.49304205 08.

Nordin, N. and Norman, H. (2017, 20-21 November). Mapping the fourth industrial revolution global transformations on $21^{\text {st }}$ century education. Paper presented at The $2^{\text {nd }}$ of International Conference on Education and Regional Development 2017.

Ornstein A.C. and Hunkins, F.P. (2013). Curriculum foundations, principles, and issues - sixth ddition. United States of America: Pearson. 
Pelgrum, W.J. (2001). Obstacles to the integration of ICT in education: Results from a worldwide educational assessment. Computers \& Education, 37(2001), 163-178.

Perpres No.131 Tahun 2013 tentang Penetapan Daerah Tertinggal Tahun 2015-2019.

Permendikbud No.81A Tahun 2013 tentang Implementasi Kurikulum.

Rizvi, F., Engel, L., Nandyala, A., Rutkowski, D., \& Sparks, J. (2005). Globalization and recent shifts in educational policy in the Asia Pacific: An overview of some critical issues. Retrieved from http://unesdoc.unesco.org/images/00 15/001529/152964e.pdf.

Seels, B. B., \& Richey, R. C. (1994). Instructional technology: The definition and domains of the field. Washington, DC: Association for Educational Communications and Technology.

Shahmir, S., Hamidi, F., Bagherzadeh, Z., and Salimi, L. (2010). Role of ICT in the curriculum educational system. Procedia Computer Science, 3(2011), 623-624. doi:10.1016/j.procs.2010.12.104.

Smaldino, S.E. (2011). Preparing students with $21^{\text {st }}$ century ICT literacy in math and science education. Journal of Curriculum and Instruction, 5:1, 1-3. doi:10.3776/joci.2011.v5n1p1-3

Somekh, B. (2007). Pedagogy and learning with ICT. London and New York: Routledge Taylor \& Francis Group.

Sudjana. (2013). Metode statistika. Bandung: PT Tarsito Bandung.

Sutherland, R., Robertson, S. and John, P. (2009). Improving classroom learning with ICT. London and New York: Routledge.

The Organization for Economic Cooperation and Development. (2013). Glossary of statistical terms: Globalization. Retrieved from https://stats.oecd.org/glossary/detail. asp?ID=1121.
Theodorou, E., Philippou, S. and Kontovourki, S. (2017). Caught between worlds of expertise: Elementary teachers amidst official curriculum development processes in Cyprus. Curriculum Inquiry. doi: 10.1080/03626784.2017.1283591.

Tinio, V.L. (2003). ICT in education. Asia Pasific: UNDP Asia Pasific Development Information Programme.

Tondeur, J. van Braak, J. and Valcke, M. (2007). Curricula and the use of ICT in education: Two world apart. British Journal of Educational Technology, 38(6), 962-976. doi: https://doi.org/10.1111/j.14678535.2006.00680.x

Undang-Undang No.14 Tahun 2005 tentang Guru dan Dosen.

UNESCO. (2013). UNESCO handbook on education policy analysis and programming. Bangkok: UNESCO.

UNESCO. (2016). The 4th industrial revolution must be a development revolution - UNESCO at Davos. Retrieved from https://en.unesco.org/news/4thindustrial-revolution-must-bedevelopment-revolution-unescodavos- 0 .

Warsihna, J. (2013). Pemanfaatan teknologi informasi dan komunikasi (TIK) untuk pendidikan di daerah terpencil, tertinggal, dan terdepan (3T). Jurnal Teknodik, 17(2), 238-245.

We Are Social. (2017). Digital in Southeast Asia in 2017. Retrieve from https://wearesocial.com/specialreports/digital-southeast-asia-2017.

Wong, L. (Ed). (2006). Globalization and education for sustainable development sustaining the future. Retrieved from http://unesdoc.unesco.org/images/00 14/001492/149295e.pdf. 